\title{
Sistem Pendukung Keputusan Menentukan Kualitas Kinerja Dosen Selama Kuliah Online Menggunakan Promethee II
}

\author{
Ita Arfyanti*, Rajiansyah \\ STMIK Widya Cipta Dharma, Samarinda, Indonesia \\ Email: 1,*ita@wicida.ac.id, 2rajiansyah@wicida.ac.id \\ Email Penulis Korespondensi: ita@wicida.ac.id
}

\begin{abstract}
Abstrak-Kinerja dosen merupakan kualitas diri yang diberikan sepeuhnya untuk memenuhi tanggung jawab seseorang pendidik diperguruan tinggi, terhadap peserta didik atau mahasiswa dalam memenuhi hak-hak mahasiswa, pentingnya diketahui kualitas Kinerja dosen akan mempengaruhi tingkat keinginan belajar mahasiswa terutama ketika masa pandemic covid-19, Kinerja dosen dianggap mampu memperbaiki proses pembelajaran yang harus dilakukan secara online, kerap sekali pembelajaran secara online mengakibatkan kurangnya komunikasi yang terjalin antara dosen dan mahasiswa. Dilakukan akumulasi terhadap sebuah sistem pendukung keputusan untuk melihat masing-masing kulitas kinerja dosen pada STMIK Widya Cipta Dharma selama kuliah online menggunakan metode promethee II, pada hasil yang ditampilkan nilai tertinggi sebesar "4,208625" menunjukan tingginya terhadap persentase pencapaian Kinerja dosen yang sebelumnya telah dilakukan perhitungan berdasarkan kriteria yang telah ditentukan yaitu disipli dosen, waktu pengajaran, penampaian materi, jabatan akademik, kesesuaian pengajaran menggunakan silabus.
\end{abstract}

Kata Kunci: Kinerja Dosen; SPK; Metode Promethee II

Abstract-Lecturer performance is a quality of self that is given entirely to fulfill the responsibilities of a teacher in a tertiary institution, towards students or students in fulfilling student rights, the importance of knowing that the quality of lecturer performance will affect the level of student learning desire, especially during the Covid-19 pandemic, lecturer performance considered capable of improving the learning process that must be done online, online learning often results in a lack of communication between lecturers and students. Accumulation was carried out on a decision support system to see each of the lecturers 'performance qualities at STMIK Widya Cipta Dharma during online lectures using the Promethee II method, the results displayed were the highest score of "4.208625" indicating a high percentage of achievement of lecturers' performance previously had calculations are carried out based on predetermined criteria, namely lecturer discipline, teaching time, material presentation, academic position, suitability of teaching using the syllabus.

Keywords: Lecturer Performance; SPK; Promethee II Method

\section{PENDAHULUAN}

Penilaian Kinerja kerja merupakan kegiatan yang biasa dilakukan oleh banyak kalangan baik dalam instansi pemerintahan maupun non pemerintahan, dunia usaha dan dunia industry yang bertujuan agar tercapainya standartstandart yang telah ditentukan pimpinan dalampemenuhan jamina mutu yang telah diterapkan dan diberikan oleh masing-masing pekerja, pentingnya dilakukan penilaian juga berupaya agar terus menigkatkan dan membuat inovasi baru terhadap pencapaian tujuan dari sebuah organisasi bersama, semakin baik Kinerja yang diberikan semakin menunjukan kualitas diri dari individu dan perusahaan yang dinaungi, pada penilaian Kinerja juga diterapkan didalam dunia pendidikan salah satunya dunia pendidikan tinggi dimana Kinerja kerja dosen merupakan salah satu aspek paling vital yang harus mampu dikelola terutama dalam kedaan era pandemi covid19.

Pada masa pandemi covid-19, mengakibatkan proses pembelajaran pada STMIK Widya Cipta Dharma harus dilakukan secara daring atau secara online sebagai upaya yang telah diatur oleh pemerintahan untuk membantu program pemerintahan dalam dan luar negeri dalam pemutusan tali rantai penyebaran covid-1, pemeblajaran online yang dilakukan seluruh aktivasi dunia pendidikan mengakibatkan banyaknya ketertinggalan dan miss komunikasi antara dosen dan mahasiswa dan tutuntan teknologi yang semakin berkembang mengakibatkan harus menuntut mahasiswa dan dosen mampu menguasai situasi dan kondisi yang tengah melanda, sering sekali akibat pembelajaran online ini membuat dosen kewalahan dan merasa malas-malasan untuk melakukan pengajaran secara optimal, bahaya yang akan timbul dari dosen yang tidak memberikan hasil kerja yang maksimal akan mengakibatkan mahasiswa yang diajarkan akan merasa tidak semangat berkuliah dan merasa dosen tidak mampu menangani permasalahan dan menguasai kelas dengan baik dan benar sehingga perlu ditinjau secara khusus dalam melakukan penilaian terhadap kualitas Kinerja dosen[1].

Melakukan penilaian terhadap kualitas kinerja dosen adalah salah satu kegiatan yang dilakukan pihak kampus atau pendidikan tinggi dalam kegiatan evaluasi kinerja kerja dari masing-masing dosen yang ada disebuah perguruan tinggi khususnya pada STMIK Widya Cipta Dharma, banyak hal yang didapatkan ketika melakukan penilaian terhadap kualitas kinerja dosen seperti, mampu memberikan motivasi untuk lebih memberikan pelayanan terabaik sebagai dosen selama proses pembelajaran, meningkatkan nilai terhadap individu, memberikan peluang terhadap kenaikan jabatan maupun pemberian penghargaan terhadap dosen yang memiliki kinerja terbaik, menigkatkan kualitas kecerdasan mahasiswa dan lain-lain yang pada akhirnya akan dilakukan evaluasi terhadap keputusan yang didapatkan oleh hasil untuk melihat apakah kualitas Kinerja dosen sudah termasuk kepada satu kesatuan pengajar yang baik atau biasas disebut dengan good teaching, hal ini perlu dilakukan untuk 
menumbuhkan standart yang tinggi sebuah akademik dan kegiatan yang ada pada pendidikan tinggi merupakan kegiatan yang mahal sehingga suatu hal yang mahal harus memiliki kualitas yang sepadan[2].

Penilaian terhadap kualitas kinerja dosen biasanya dilakukan selama priode setahun sekali pada prosesnya nantinya akan dilakukan penilian terhadap dosen dimana mahasiswa lah sebagai indikator dan sumber dari penilaiannya dimana pada penilaiaannya berdasarkan beberapa kriteria seperti disipli dosen, waktu pengajaran, penampaian materi, jabatan akademik, kesesuaian pengajaran menggunakan silabus yang akan dikelola menggunakan penerapan sistem pendukung keputusan dimana hasil yang diperoleh akan lebih objektif dan efektif terhadap penentuan kualitas kerja dosen [3].

Penentuan kualitas kerja dosen akan dilakukan pendekatan terhadap metode Promethee II sebagai acuan dalam membantu mengolah antara kriteria-kriteria ataupun acuan yang menjadi penilaian terhadap penentuan kualitas Kinerja dosen dengan melakukan penerapan terhadap pembobotan yang bersifat penting disetiap kriteria yang ada, dan penelitian menggunakan metode promethee II merupakan metode yang paing efektif digunakan banyak kalangan dan penelitian-penelitian terdahulu dikarenakan tingkat akurasi dalam membantu penyelesaian masalah pengambilan keputusan sehingga banyak penelitian terdahulu melakukan penelitian dengan menggunakan metode Promethee II seperti "Penerapan Metode Promethee II Pada Sistem Layanan Dan Rujukan Terpadu (SLRT) Studi Kasus Dinas Social Kabupaten Deli Serdang”, "sistem pendukung keputusan pemilihan produk lensa kacamata menggunakan metode promethee II", "Influence of various normalization methods in PROMETHEE II: an empirical study on the selection of the airport location"[4]-[6].

\section{METODOLOGI PENELITIAN}

Setiap penelitian diperlukan metodologi penelitian untuk mengetahui rancangan dan tahapan penelitian yang dilakukan agar dalam sebuah penelitian penelitian lebih terarah dan mendapatkan hasil yang valid, pada penelitian ini dilakukan penerapan terhadap metode kuantitatif yang melakukan pengujian data seara sistematik dan bersifat matematik dari hasil pengolahan data statistik yang sebelumnya dilakukan beberapa tahapan mulai dari pengumpulan data hingga teori terhadap pendekatan topik dan teoristis tehadap pembahasan yang akan di uji[7].

\subsection{Teknik Pengumpulan Data}

Pada pengumpulan data dilakukan tahapan sebagai berikut ini[8]:

1. Kuesioner

Kuesioner merupakan beberapa pertanyaan yang dirangkum demi mendapatkan pernyataan dari sumber pendukung untuk mencapapi data target yang akan diuji, pada penelitian ini kuesioner dibagiakan kepada mahasiswa-mahasiswi pendidikan tinggi dan mereka nantinya akan menjawab butir-butir pertanyaan dengan kesadaran penuh, kuesioner dapat berisi pertanyaan dengan jawaban berupa teks maupun angka atau range yang akan diberikan kepada dosen terkait.

2. Dokumentasi

Dokumentasi dilakukan agar tidak kehilangan data yang berhubngan dengan data-data penting lainnya untuk menyatakan bahwasannya pengujian benar dilakukan, dan dokumen biasanya bersifat dapat diperoleh kembali jika suatu saat dibutuhkan kelengkapan data pendukung pada saat pengujian.

3. Studi pustaka

Studi pustaka digunakan untuk memperlihatkan banyak penelitian terdahulu yang baik bersumber dari karya ilmiah seperti buku, artikel ilmiah jurnal-jurnal yang berkaitan dengan pengujian sebagai pemandu dan penunjang bahwa penelitian ini dilakukan dengan data-data yang telah digunakan sebelumnya dan dilakukan pengenbangan terhadap pengujian yang akan dilakukan. Pentingnya studi pustaka agar penulis maupun peneliti kedepannya dapat menambah wawasan dan pengetahuan lebih dalam membantu menyelesaikan penelitiannya.

\subsection{Kinerja Dosen}

Kinerja dosen merupakan cara kerja dan penilaian terhadap cara mengajar dosen yang dilihat dari beberapa aspek dimana Kinerja ini dirasakan langsung oleh mahasiswa, Kinerja dosen juga dikatakan sebagai tampilan performa yang diberikan dosen dalam menekuni dan menjalankan setiap kewajibannya sebagai dosen baik dalam proses mengajar maupun dalam mematuhi segala peraturan yang telah diterapkan oleh tempat mengabdi seorang dosen dalam sebuah lingkuang pendidikan tinggi. Kinerja dosen yang akan memperlihatkan bagaimana dedikasi dan pengabdian dosen selama ini diterapkan[2].

\subsection{Sistem Pendukung Keputusan}

Sistem pendukung keputusan merupakan ilmu teknologi yang membantu dalam menyelesaikan masalah terhadap pengambilan keputusan dengan model interaktif terhadap penyediaan dan penyajian data dan mampu memanipulasi data dengan menghasilkan keputusan yang tepat berdasarkan sistem, pada sistem ini dibentuk dengan menggunakan sistem komputerisasi dimana keputusan bersifat mutlak dan berdasarkan nilai yang masingmasing kandidat atau objek penentuan sudah ditentukan, pada sistem pendukung keputusan terdapat banyak jenis 
metode sebagai pendekatan terhadap stategi penyelesaian permasalahan menggunakan sistem pendukung keputusan, metode yang diterapkan nantinya akan menghitung secara keseluruhan data secara statisik dan menghasilkan data yang nyata dan benar-benar dari data yang diinputkan[9]-[12].

\subsection{Preference Ranking Organization Method for Enrichment Evaluation (PROMETHEE II)}

Promethee II atau singkatan dari Preference Ranking Organization Method For Enrichment Evaluation adalah salah satu metode decision making dimana hasil yang dilakukan pada pengujian ini yang diambil adalah nilai perangkingan tertinggi, promethee II menawarkan cara kerja sistem yang sederhana dan lebih fleksibel dalam membantu para peneliti dalam meganalisis masalah multikriteria dan nilai terbaik maupun nilai tertinggi merupakan keputusan yang paling wajib diambil sebagai keputusan yang terpilih, berikut merupakan tahapan dalam menyelesaikan kasus menggunakan perhitungan Promethee II[6][13]-[18]:

1. Normalisai Matriks

Perhitungan Benefit dilakukan jika terdapat nilai kriteria dengan unsur menguntungkan:

$$
\begin{aligned}
r_{i j} & =\frac{\left[x_{i j}-\min \left(x_{i j}\right)\right]}{\left[\max \left(x_{i j}\right)-\min \left(x_{i j}\right)\right)} \text { jika merupakan nilai Benefit } \\
r_{i j} & =\frac{\left[\max \left(x_{i j}\right)-x_{i j}\right]}{\left[\max \left(x_{i j}\right)-\min \left(x_{i j}\right)\right)} \text { jika merupakan nilai Cost }
\end{aligned}
$$

2. Menghitung fungsi Preferensi $P_{j\left(i, i^{\prime}\right)}$

$$
\begin{aligned}
& P_{j\left(i, i^{\prime}\right)}=0 \text { if } r_{i j} \leq r_{i \prime j} \\
& \operatorname{Dan} P_{j\left(i, i^{\prime}\right)}=\left(r_{i j} \leq r_{i^{\prime} j}\right) \text { if } r_{i j} \leq r_{i^{\prime} j}
\end{aligned}
$$

3. Menghitung preferensi Agregat

$$
W P(i, i)=\left[\sum_{j=1}^{n} W_{j} \times P_{j}(i, i)\right] \sum_{j=1}^{n} W_{j}
$$

4. Penentuan arus keluaran dan arus masuk

a. Aliran positif pada alternative

b. Alir negatif pada alternative

$$
\varphi^{+}(i)=\frac{1}{m-1} \sum_{j=1}^{1} \operatorname{TP}\left(i, i^{\prime}\right)\left(i \neq i^{\prime}\right)
$$

$$
\varphi^{-}(i)=\frac{1}{m-1} \sum_{j=1}^{1} \operatorname{TP}\left(i, i^{\prime}\right)\left(i \neq i^{\prime}\right)
$$

5. Mencari Hasil Akhir

$$
\varphi(i)=\varphi^{+}(i)-\varphi^{-}(i)
$$

\section{HASIL DAN PEMBAHASAN}

Langkah awal yang dilakukan dalam menentukan kualitas kinerja dosen harus mengetahui siapa dan apa saja yang menjadi alternatif dan juga kriteria yang ingin diketahui setelah itu dilakukan langkah-langkah menggunakan promethee II untuk mengetahui nilai tertinggi yang pada akhirnya akan memperlihatkan kualitas kinerja dosen berdasarkan nilai persentase atau rank yang didapat setelah melakukan perhitungan.

\subsection{Alternatif dan kriteria}

Alternatif merupakan pilihan pada kasus ini alternatif merupakan kandidat yang akan dipilih untuk melihat kualitas kinerja dosen sementara kriteria meruapa hal-hal atau nilai pendukung yang dimiliki masing-masing kandidat sebagai berikut.

1. Tabel Kriteria

Pada tabel ini akan menjelaskan tentang jenis kriteria dan bobot yang dimiliki oleh masing-masing kriteria yang ditetapkan pada STMIK Widya Cipta Dharma.

Tabel 1. Kritera

\begin{tabular}{clcc}
\hline Kode & \multicolumn{1}{c}{ Alternatif } & Tipe & Bobot \\
\hline C1 & $\begin{array}{l}\text { Dosen selalu Disiplin dan tepat waktu sesuai } \\
\text { dengan kontrak perkuliahan }\end{array}$ & Benefit & 2 \\
C2 & $\begin{array}{l}\text { Dosen Terus memberikan materi dan } \\
\text { menerangkan materi dengan baik }\end{array}$ & Benefit & 2,5 \\
C3 & Sesuia dengan Silabus & Benefit & 3 \\
\hline
\end{tabular}


JURNAL MEDIA INFORMATIKA BUDIDARMA

Volume 5, Nomor 2, April 2021, Page 652-658

ISSN 2614-5278 (media cetak), ISSN 2548-8368 (media online)

Available Online at https://ejurnal.stmik-budidarma.ac.id/index.php/mib DOI $10.30865 /$ mib.v5i2.2942

\begin{tabular}{clcc}
\hline Kode & \multicolumn{1}{c}{ Alternatif } & Tipe & Bobot \\
\hline C4 & $\begin{array}{l}\text { Interasi antara mahasiswa dan dosen selama } \\
\text { masa pembelajaran dengan baik }\end{array}$ & Benefit & 2,5 \\
\hline
\end{tabular}

Berikut ini merupakan alternatif dan nilai pada kriteria

Tabel 2. Altenatif dan Kriteria

\begin{tabular}{lllll}
\hline \multirow{2}{*}{ Alternatif } & \multicolumn{4}{c}{ Kriteria } \\
\cline { 2 - 5 } & C1 & C2 & C3 & C4 \\
\hline A1 & Sangat Baik & Baik & Sangat Baik & Cukup Baik \\
A2 & Cukup Baik & Sangat Baik & Baik & Baik \\
A3 & Buruk & Cukup Baik & Sangat Baik & Buruk \\
A4 & Baik & Buruk & Cukup Baik & Cukup Baik \\
A5 & Sangat Baik & Baik & Baik & Sangat Baik \\
\hline
\end{tabular}

\subsection{Tahapan Promethee II}

Setelah diketahui alternatif dan kriteria yang digunakan selanjutnya melakukan perhitungan menggunakan metode the extended promethee II. Sebelumnya lakukan perantian dari keterangan data huruf menjadi angka dalam range yang telah ditentukan.

Tabel 3. Keterangan Nilai Pernyataan

\begin{tabular}{cc}
\hline Keterangan & Nilai \\
\hline Sangat baik & 10 \\
Baik & 8 \\
Cukup Baik & 6 \\
Buruk & 4 \\
Sangat Buruk & 2 \\
\hline
\end{tabular}

Berikut ini merupakan data yang sudah dirubah kedalam bentuk angka agar mudah melakukan proses terhadap perhitungan mengguanak metode Promethee II.

Tabel 4. Altenatif dan Kriteria

\begin{tabular}{lllll}
\hline \multirow{2}{*}{ Alternatif } & \multicolumn{4}{c}{ Kriteria } \\
\cline { 2 - 5 } & C1 & C2 & C3 & C4 \\
\hline A1 & 10 & 8 & 10 & 6 \\
A2 & 6 & 10 & 8 & 8 \\
A3 & 4 & 6 & 10 & 4 \\
A4 & 8 & 4 & 6 & 6 \\
A5 & 10 & 8 & 10 & 10 \\
\hline
\end{tabular}

1. Matriks Keputusan

$\left[\begin{array}{cccc}10 & 8 & 10 & 6 \\ 6 & 10 & 8 & 8 \\ 4 & 6 & 10 & 4 \\ 8 & 4 & 6 & 6 \\ 10 & 8 & 10 & 10\end{array}\right]$

Maximal Nilai setiap kriteria $\mathrm{C} 1=10, \mathrm{C} 2=10, \mathrm{C} 3=10$ dan $\mathrm{C} 4=10$

Minimum Nilai setiap kriteria $\mathrm{C} 1=4, \mathrm{C} 2=4, \mathrm{C} 3=6$ dan $\mathrm{C} 4=4$

Normalisasi Terhadap Matriks

$\mathrm{C} 1=$ Kehadiran dengan jenis benefit

$R_{11}=\frac{10-4}{10-4}=1$

$R_{21}=\frac{6-4}{10-4}=0,3333$

$R_{31}=\frac{4-4}{10-4}=0$

$R_{41}=\frac{8-4}{10-4}=0,666$

Lakukan perhitungan hingga habis sehingga didapatkan nilai sebagai berikut 
JURNAL MEDIA INFORMATIKA BUDIDARMA

Volume 5, Nomor 2, April 2021, Page 652-658

ISSN 2614-5278 (media cetak), ISSN 2548-8368 (media online)

Available Online at https://ejurnal.stmik-budidarma.ac.id/index.php/mib DOI 10.30865/mib.v5i2.2942

$$
\left[\begin{array}{cccc}
1 & 0,666 & 1 & 0,333 \\
0,333 & 1 & 0,5 & 0,666 \\
0 & 0,333 & 1 & 0 \\
0,666 & 0 & 0 & 0,333 \\
1 & 0,666 & 1 & 1
\end{array}\right]
$$

2. Langkah kedua yatu mencari nilai fungsi preferensi sebagai berikut ini:

Tabel 5. Hasil Nilai Fungs Preferensi

\begin{tabular}{rrrr}
\hline 0,667 & 0 & 0,5 & 0 \\
1 & 0,333 & 0 & 0,333 \\
0,334 & 0,666 & 1 & 0 \\
0 & 0 & 0 & 0 \\
0 & 0,334 & 0 & 0,333 \\
0,333 & 0,667 & 0 & 0,666 \\
0 & 1 & 0,5 & 0,333 \\
0 & 0,334 & 0 & 0 \\
0 & 0 & 0 & 0 \\
0 & 0 & 0,5 & 0 \\
0 & 0,333 & 1 & 0 \\
0 & 0 & 0 & 0 \\
0 & 0 & 0 & 0 \\
0,333 & 0 & 0 & 0 \\
0,666 & 0 & 0 & 0,333 \\
0 & 0 & 0 & 0 \\
0 & 0 & 0 & 0,667 \\
0,667 & 0 & 0,5 & 0,334 \\
1 & 0,333 & 0 & 1 \\
0,334 & 0,666 & 1 & 0,667 \\
\hline
\end{tabular}

3. Mencari nilai fungsi preferensi agregrat

Pada tahapan ini hasil dari fungsi preferensi selanjutnya dikalikan dengan masing-masing bobot yang dimiliki pada masing-masing kriteria sehingga hasi yang didapatkan sebagai berikut ini:

Tabel 6. Hasil Nilai Preferensi Agregat

\begin{tabular}{cccccc}
\hline Alternatif & $\mathrm{C} 1$ & $\mathrm{C} 2$ & $\mathrm{C} 3$ & $\mathrm{C} 4$ & Total \\
\hline P1,2 & 1,334 & 0 & 1,5 & 0 & 2,834 \\
P1,3 & 2 & 0,8325 & 0 & 0,8325 & 3,665 \\
P1,4 & 0,668 & 1,665 & 3 & 0 & 5,333 \\
P1,5 & 0 & 0 & 0 & 0 & 0 \\
P2,1 & 0 & 0,835 & 0 & 0,8325 & 1,6675 \\
P2,3 & 0,666 & 1,6675 & 0 & 1,665 & 3,9985 \\
P2,4 & 0 & 2,5 & 1,5 & 0,8325 & 4,8325 \\
P2,5 & 0 & 0,835 & 0 & 0 & 0,835 \\
P3,1 & 0 & 0 & 0 & 0 & 0 \\
P3,2 & 0 & 0 & 1,5 & 0 & 1,5 \\
P3,4 & 0 & 0,8325 & 3 & 0 & 3,8325 \\
P3,5 & 0 & 0 & 0 & 0 & 0 \\
P4,1 & 0 & 0 & 0 & 0 & 0 \\
P4,2 & 0,666 & 0 & 0 & 0 & 0,666 \\
P4,3 & 1,332 & 0 & 0 & 0,8325 & 2,1645 \\
P4,5 & 0 & 0 & 0 & 0 & 0 \\
P5,1 & 0 & 0 & 0 & 1,6675 & 1,6675 \\
P5,2 & 1,334 & 0 & 1,5 & 0,835 & 3,669 \\
P5,3 & 2 & 0,8325 & 0 & 2,5 & 5,3325 \\
P5,4 & 0,668 & 1,665 & 3 & 1,6675 & 7,0005 \\
\hline
\end{tabular}

4. Ketika sudah dibuat dalam bentuk tabel selanjutnya nilai secara baris dan kolom akan di totalkan untuk melihat melakukan perhitungan tahapan 4 yaitu menghitung arus keluaran dan arus masukan 
ISSN 2614-5278 (media cetak), ISSN 2548-8368 (media online)

Available Online at https://ejurnal.stmik-budidarma.ac.id/index.php/mib DOI 10.30865/mib.v5i2.2942

Tabel 7. Perhitungan dan penjumlahan nilai

\begin{tabular}{ccccccc}
\hline Alternatif & A1 & A2 & A3 & A4 & A5 & Total \\
\hline A1 & - & 2,834 & 3,665 & 5,333 & 0 & 11,832 \\
A2 & 1,6675 & - & 3,9985 & 4,8325 & 0,835 & 11,3335 \\
A3 & 0 & 1,5 & - & 3,8325 & 0 & 5,3325 \\
A4 & 0 & 0,666 & 2,1645 & - & 0 & 2,8305 \\
A5 & 1,6675 & 3,669 & 5,3325 & 7,0005 & - & 17,6695 \\
Total & 3,335 & 8,669 & 15,1605 & 20,9985 & 0,835 &
\end{tabular}

a. Menghitung Nilai Entering

$$
\begin{aligned}
\varphi^{+} & =\frac{1}{5-1} \times 11,832=2,958 \\
\varphi^{+} & =\frac{1}{5-1} \times 11,3335=2,833375 \\
\varphi^{+} & =\frac{1}{5-1} \times 5,3325=1,333125 \\
\varphi^{+} & =\frac{1}{5-1} \times 2,8305=0,707625 \\
\varphi^{+} & =\frac{1}{5-1} \times 17,6695=4,417375
\end{aligned}
$$

b. Menghitung Nilai Leaving Flow

$$
\begin{aligned}
& \varphi^{-}=\frac{1}{5-1} \times 3,335=0,83375 \\
& \varphi^{-}=\frac{1}{5-1} \times 8,669=2,16725 \\
& \varphi^{-}=\frac{1}{5-1} \times 15,1605=3,790125 \\
& \varphi^{-}=\frac{1}{5-1} \times 20,9985=5,249625 \\
& \varphi^{-}=\frac{1}{5-1} \times 0,835=0,20875
\end{aligned}
$$

5. Menghitung Net Flow

Pada perhitungan hasil akhir merupakan keputussan dari penilaian dan penilaian tertinggi merupakan angka presentasi terbaik

Tabel 8. Net Flow

\begin{tabular}{lrcrc}
\hline Alternatif & \multicolumn{1}{c}{$(+)$} & $(-)$ & \multicolumn{1}{c}{$\boldsymbol{\varphi}(\boldsymbol{i})$} & Rank \\
\hline A1 & 2,958 & 0,83375 & 2,12425 & 2 \\
A2 & 2,833375 & 2,16725 & 0,666125 & 3 \\
A3 & 1,333125 & 3,790125 & $-2,457$ & 4 \\
A4 & 0,707625 & 5,249625 & $-4,542$ & 5 \\
A5 & 4,417375 & 0,20875 & 4,208625 & 1 \\
\hline
\end{tabular}

Dari tabel 8 dapat dilihat bahwa kinerja dosen A5 lebih tinggi disbanding dosen yang lainnya.

\section{KESIMPULAN}

Pada penelitian diatas dapat ditarik kesimpulan nilai tertinggi berada pada alternatif A4 yaitu kandidat Ardin Azhar yang menjadi dosen yang memiliki Kualitas Kinerja dosen yang paling tertinggi, pada penilaian, dengan adanya sistem ini pemberian nilai terhadap kualitas Kinerja dosen lebih dapat dilakukan dengan cara yang adil dan sesuai kepada penilaian dengan masing-masing nilai yang dimiliki oleh alternatif sehingga memberikan nilai yang tidak melenceng dan bersifat mutlak, penggunaan metode ini sangat sederhana dengan tingkat penilaian lebih selektif pada tahapan penyelesaian kasus. Penelitian ini dapat dijadikan sumber referensi dalam mengetahui tahapan penyelesaian menggunakan metode promethee II yang cukup sederhana, pada pemberian bobot dapat dilakukan pengujian menggunakan bantuan metode lain dan pada tahapan metode ini bobot tergantung kepada penilaian dan syarat yang diinginkan pihak pengujian.

\section{REFERENCE}

[1] J. Kirana, K. P. Rajagukguk, E. Lailan, and S. Lubis, “ANALISIS DAMPAK COVID-19 PADA MASYARAKAT," vol. 1, pp. 64-69, 2020.

[2] Yoga Handoko Agustin and H. Kurniawan, "Sistem Pendukung Keputusan Penilaian Kinerja Dosen Menggunakan Metode Weighted Product (Studi Kasus : Stmik Pontianak)," Semin. Nas. Inform. 2015, pp. 177-182, 2015.

[3] D. I. K. SURYADI and M. T. IR. M. ALI RAMADHANI, SISTEM PENDUKUNG KEPUTUSAN, SISTEM PEN. Bandung: PT Remaja Rosdakarya Bandung, 1998.

[4] M. Mesran, I. Saputra, and M. Ariska, "Penerapan Metode Promethee Ii Pada Sistem Layanan Dan Rujukan Terpadu ( 
Slrt ) ( Studi Kasus : Dinas Sosial Kabupaten Deli Serdang )," KOMIK (Konferensi Nas. Teknol. Inf. dan Komputer), vol. I, pp. 276-285, 2017.

[5] E. Novida and H. Sunandar, "Sistem Pendukung Keputusan Pemilihan Produk Lensa Kacamata Menggunakan Metode Promethee Ii," J. Pelita Inform., vol. 17, no. 1, pp. 71-78, 2018.

[6] K. Palczewski and W. Sałabun, "Influence of various normalization methods in PROMETHEE II : an empirical study on the selection of the airport location ScienceDirect Influence Influence of of various various normalization normalization methods methods in in PROMETHEE PROMETHEE II : II ," Procedia Comput. Sci., vol. 159, no. October, pp. 20512060, 2019.

[7] Albi Anggito and Johan Setiawan, Metodologi Penelitian Kuantitatif. Jawa Barat: CV Jejak, 2018.

[8] H. Hasanah, "TEKNIK-TEKNIK OBSERVASI (Sebuah Alternatif Metode Pengumpulan Data Kualitatif Ilmu-ilmu Sosial)," At-Taqaddum, vol. 8, no. 1, p. 21, 2017.

[9] kursini, Konsep Dan Aplikasi Sistem Pendukung Keputusan. Yogyakarta: Andi, 2017.

[10] T. Limbong et al., Sistem Pendukung Keputusan: Metode \& Implementasi. Medan: Yayasan Kita Menulis, 2020.

[11] D. Nofriansyah and S. Defit, Multi Criteria Decision Making (MCDM) pada Sistem Pendukung Keputusan. 2018.

[12] Efraim Turban and Jay E. Aronson, Decision Support System and Intelligent Systems. 2001.

[13] M. Mesran, S. D. Nasution, S. Syahputra, A. Karim, and E. Purba, "Implementation of the Extended Promethee II in Upgrade Level of Mechanic," Int. J. Sci. Res. Sci. Technol., vol. 4, no. 2, pp. 125-130, 2018.

[14] N. Nurlela, M. Syahrizal, F. Fadlina, and A. Karim, "Sistem Pendukung Keputusan Pemilihan Kepala Desa Terbaik Menerapkan Metodethe Extended Promethee II (EXPROM II)," J. Sist. Komput. dan Inform., vol. 1, no. 3, p. $200,2020$.

[15] C. Astria, K. F. Irnanda, and A. P. Windarto, "Penerapan Algortima PROMETHEE II Pada Pemilihan Media Sosial untuk Bisnis Online," vol. 13, no. 2, 2018.

[16] D. Assrani, M. Mesran, R. D. Sianturi, Y. Yuhandri, and A. Iskandar, "Sistem Pendukung Keputusan Pemilihan Guru Produktif Peserta Pelatihan Asesor Kompetensi Lsp P1 Smk Swasta Dwiwarna Medan Menggunakan Metode the Extended Promethee Ii (Exprom Ii)," KOMIK (Konferensi Nas. Teknol. Inf. dan Komputer), vol. 2, no. 1, 2018.

[17] Y. Silalahi, M. Mesran, T. Zebua, and S. Suginam, "PENERAPAN THE EXTENDED PROMETHEE II ( EXPROM II ) UNTUK PENENTUAN PRODUK DISKON," KOMIK (Konferensi Nas. Teknol. Inf. dan Komputer), vol. I, no. 1, 2017.

[18] M. Mesran, P. Pristiwanto, and I. Sinaga, "Implementasi Promethee II Dalam Pemilihan Pestisida Terbaik Untuk Perawatan Daun Pada Tanaman Cabe,” CESS (Journal Comput. Eng. Syst. Sci., vol. 3, no. 2, pp. 46-53, 2018. 